\title{
Ethno-Specific Risk Factors for Adverse Pregnancy Outcomes: Findings from the Born in Bradford Cohort Study
}

\author{
Tomasina Stacey $^{1} \cdot$ Stephanie Prady $^{2} \cdot$ Melanie Haith-Cooper ${ }^{3} \cdot$ Soo Downe $^{4} \cdot$ \\ Nigel Simpson ${ }^{5} \cdot$ Kate Pickett $^{2}$
}

Published online: 16 March 2016

(C) The Author(s) 2016. This article is published with open access at Springerlink.com

\begin{abstract}
Objectives Preterm birth (PTB) and small for gestational age (SGA) are major causes of perinatal mortality and morbidity. Previous studies indicated a range of risk factors associated with these poor outcomes, including maternal psychosocial and economic wellbeing. This paper will explore a range of psycho-social and economic factors in an ethnically diverse population. Methods The UK's Born in Bradford cohort study recruited pregnant women attending a routine antenatal appointment at 26-28 weeks' gestation at the Bradford Royal Infirmary (2007-2010).
\end{abstract}

Tomasina Stacey

t.stacey@leeds.ac.uk

Stephanie Prady

stephanie.prady@york.ac.uk

Melanie Haith-Cooper

mcooper2@bradford.ac.uk

Soo Downe

sdowne@uclan.ac.uk

Nigel Simpson

n.a.b.simpson@leeds.ac.uk

Kate Pickett

kate.pickett@york.ac.uk

1 School of Healthcare, University of Leeds, Leeds LS2 9JT, UK

2 Department of Health Sciences, University of York, Heslington, York, Yorkshire YO10 5DD, UK

3 School of Health Studies, University of Bradford, Richmond Road, Bradford, Yorkshire BD7 1DP, UK

4 School of Health, University of Central Lancashire, Brook Building, Preston PR1 2HE, UK

5 Department of Women's and Children's Health, Level 9, University of Leeds, Worsley Building, Clarendon Way, Leeds LS2 9NL, UK
This analysis includes 9680 women with singleton live births who completed the baseline questionnaire. Data regarding maternal socio-demographic and mental health were recorded. Outcome data were collected prospectively, and analysed using multivariate regression models. The primary outcomes measured were: PTB $(<37$ weeks' gestation) and SGA ( $<10$ th customised centile). Results After adjustment for socio-demographic and medical factors, financial strain was associated with a $45 \%$ increase in PTB (OR 1.45: $95 \%$ CI 1.06-1.98). Contrary to expectation, maternal distress in Pakistani women was negatively associated with SGA (OR 0.65: CI 0.48-0.88). Obesity in White British women was protective for PTB (OR 0.67: CI 0.45-0.98). Previously recognized risk factors, such as smoking in pregnancy and hypertension, were confirmed. Conclusions This study confirms known risk factors for PTB and SGA, along with a new variable of interest, financial strain. It also reveals a difference in the risk factors between ethnicities. In order to develop appropriate targeted preventative strategies to improve perinatal outcome in disadvantaged groups, a greater understanding of ethno-specific risk factors is required.

Keywords Small for gestational age - Preterm birth . Born in Bradford · Depression · Financial strain · Ethnic differences

\section{Significance}

\section{What is Already Known on this Topic?}

A number of risk factors have been identified for small for gestational age and preterm birth. These have included some psycho-social factors. The rates of these adverse 
outcomes differ between ethnic groups, with the most socially disadvantaged groups being most at risk.

\section{What this Study Adds}

This paper finds an association between maternal financial strain and risk of preterm birth that is as high as that for smoking. It also suggests that there is a difference in risk factors between ethnicities.

Preterm birth ( $<37$ weeks of gestation) (PTB) is a major cause of neonatal and infant mortality and morbidity. In high income countries, there has been minimal decline in the rate of preterm birth in the last few decades [29]. Small for gestational age (SGA) is also associated with an increased risk of perinatal mortality and morbidity, and poor long term health outcomes such as obesity, hypertension and other cardiovascular diseases [4, 9]. The consequences of these poor perinatal outcomes present a significant public health issue, requiring an exploration into primary prevention.

The highest rates of PTB and SGA occur in the most socially disadvantaged groups within the population [30]. In the United Kingdom, South Asian mothers have a slightly higher rate of preterm birth compared to White British mothers and their babies are twice as likely to be born with a low birthweight (below 2500 g) [21]. Known risk factors for SGA and PTB include: smoking, alcohol use, diabetes, hypertension, maternal age and body mass index [13, 15, 27]. Previous studies have suggested that maternal psychosocial health (such as chronic stress and anxiety) may also be associated with PTB and SGA [22]. It is unclear, however, whether these associations are specific to the particular populations studied, or if they are generalizable to other population groups. The development of appropriately targeted prevention strategies requires more analysis of relevant population groups. Our primary aim was therefore to explore ethno-specific risk factors for PTB and SGA, in particular in relation to psychosocial health, within an urban, multi-ethnic, socially disadvantaged cohort.

\section{Methods}

Born in Bradford (BiB) is a longitudinal multi-ethnic community birth cohort study which aims to examine how environmental, psychological and genetic factors impact on maternal and child health and wellbeing [35]. Recruitment took place between 2007 and 2010 at the Bradford Royal Infirmary (BRI). All women who attended a routine glucose tolerance test (offered to all pregnant women at 26-28 weeks' gestation) were invited to take part in the study and written consent was obtained. Baseline data were collected through an interview administered questionnaire held in a designated room. There were three phases of data collection with slight variants to the baseline questionnaire, with the General Health Questionnaire 28 (GHQ-28) [12] being administered in Phases 2 and 3. The interviews were conducted in English, Mirpuri (a spoken variant of Punjabi) or Urdu.

The questionnaire covered a wide range of socio-economic questions regarding financial security and lifestyle factors. It also included items from the GHQ-28, a commonly used screening tool for psychological distress [12]. Over $80 \%$ of women who attended the clinic were recruited $(12,453)$ and the cohort is broadly representative of the city's maternal population [35].

Ethics approval for the data collection was granted by Bradford Research Ethics Committee (Ref 07/H1302/112).

\section{Dependent Variables}

PTB was defined as birth occurring at less than 37 weeks' gestational age, based on the estimated date of delivery calculated by the dating scan (if available), or last menstrual period. SGA was defined as a birthweight less than the 10th customised centile, using GROW software from 2013, https://www.gestation.net/cc/about. htm [8]. These categorisations were derived from maternal characteristics, birthweight and gestational age data recorded in the electronic maternity system (eCLIPSE) at the BRI.

\section{Independent Variables}

Information on diabetes, hypertension, parity and body mass index (BMI) came from eCLIPSE and the remaining data from the baseline questionnaire. Data on diabetes status at booking and any subsequent diagnosis of gestational diabetes were combined to form one binary variable defining diabetic status. Data on hypertension status at booking, subsequent pregnancy-induced hypertension and/ or pre-eclampsia were combined in the same way. We calculated BMI using weight and height at first booking and created categories based on the WHO criteria [31]: underweight (<18.5), normal (18.5-24.9), overweight (25-29.9), and obese ( $\geq 30)$. Although there is suggestion that ethnic specific BMI categories might be a more appropriate measure of obesity [32], it has been found in this cohort that lowering the BMI obesity threshold for South Asian women does not improve the predictive ability to identify adverse pregnancy outcomes [6], conventional categories were therefore applied.

The definition of ethnicity in $\mathrm{BiB}$ was based on the UK's 2001 census categories (ONS 2001) and 
comprised a question asking which ethnic group the mothers considered themselves to belong to. We then classified women as White British, Pakistani or Other ethnic origin (including amongst Other; non-Pakistani Asian, African, other European and Middle Eastern women).

For those women completing the baseline questionnaire in English the GHQ-28 was administered as part of a selfcompletion module at the end of the interview for participants enrolled during Phases 2 and 3. For those who chose to have the interview in Mirpuri or Urdu, the questions were read aloud and the interviewer coded the response. We did not create a summary score threshold for distress because the measurement properties of the GHQ-28 may not be equivalent between ethnic groups in this cohort [10]. Instead, we scored the instrument using the GHQ methods $[25,26]$ and derived two indicators of distress. First, we used a non-parametric threshold to indicate women at risk of distress using the first 21 questions (relating to somatic symptoms, anxiety and insomnia, and social dysfunction) and set this at the 85th centile score within each ethno-language group (White British-English, Pakistani-English, Pakistani-Urdu, Pakistani-Mirpuri, other ethnicities-English, all other nonEnglish). Second, we took four out of the seven questions from the Severe Depression subscale of the GHQ-28 which have been found to broadly relate to the same concept across ethno-language groups [25, 26], and created an indicator which we term 'hopelessness'.

More than $35 \%$ of South Asian women in BiB did not know or did not report their household income, but they were much more likely to answer questions on financial security. "How well would you say you or you and your husband/partner are managing financially these days?" We categorised those who reported 'living comfortably', 'doing alright' or 'just getting by', as financially secure and those who responded 'finding it quite difficult' or 'very difficult' as struggling financially. Financial security has a psychosocial meaning that goes beyond material wealth and involves the extent to which the respondent perceives their income to be enough for the family cost of living.

We created a binary indicator of area deprivation from national quintiles of Index of Multiple Deprivation (IMD), classifying those in the most deprived quintile against all others. In line with other studies, marital status was classified as a binary variable: married and not married (cohabiting and single) [28]. The binary variable for education compared those with fewer than 5 GSCEs, unknown, or equivalent qualification that could not be classified, with those who achieved 5 GCSEs or higher. We also generated binary variables for smoking and drinking alcohol at any time during pregnancy.

\section{Missing Data}

In this analysis we included 9680 singleton non-anomalous births where the mother completed the baseline questionnaire and gave birth at the BRI ( $78 \%$ of the total cohort). We used the data from the first enrolled pregnancy for women who enrolled in the study more than once during the recruitment period. We did not analyse data from 72 women for whom the language in which the questionnaire was administered was not stated and where we also had no data on ethnicity.

Nearly one-third of women were missing at least one covariate, which we assumed were either randomly missing (e.g. no GHQ-28 in Phase 1) or missing dependent on observed covariates (e.g. women of Pakistani origin less likely to respond about their financial situation). To utilise the entire sample with corrected variance we imputed missing covariate data using chained equations as implemented in Stata $13(M=10)$. We included all covariates and outcomes in our imputation model, along with design variables (questionnaire phase, language of administration). For the 'risk of distress' variable, we performed a simple imputation (low score) for those missing up to 4 items $(\mathrm{N}=371)$. We included these along with respondents who had completed all the GHQ-28 data $(\mathrm{N}=7765)$ and categorised risk of psychological distress as a binary variable for all these respondents combined (total $\mathrm{N}=8136$ ). We set those missing 4 or more GHQ-28 responses to zero $(\mathrm{N}=56)$, and performed multiple imputation on both these cases and those with all scores missing $(\mathrm{N}=1634)$. Of all the participants in this category, $81.2 \%$ were enrolled in Phase 1 where the GHQ-28 was not presented. For the 'risk of hopelessness' variable, we categorised risk on all complete cases $(\mathrm{N}=8013$, $82.1 \%$ ), and imputed risk as a binary variable for all others. For the overall model, we imputed on the whole dataset and included ethnicity as a variable during the imputation process.

\section{Statistics}

We tabulated socio-demographic status by ethnic group. We then fitted unadjusted logistic regression models for the association between a covariate and each outcome of interest (SGA and PTB) for the sample as a whole and stratified by ethnic group. We then fitted fully adjusted multivariate models for the whole sample and also stratified by ethnic group. We calculated odds ratios (OR) with $95 \%$ confidence intervals $(\mathrm{CI})$ and $\mathrm{P}$ values, set at $<0.05$ for statistical significance. In this paper we present models based on the imputed dataset. We ran all models again using data from complete cases (excluding all missing data) finding results broadly similar to the imputed models. 
Table 1 Demographic data of study population

\begin{tabular}{|c|c|c|c|c|c|c|c|c|}
\hline & \multicolumn{2}{|c|}{ White British $(\mathrm{N}=3929)$} & \multicolumn{2}{|c|}{ Pakistani $(\mathrm{N}=4264)$} & \multicolumn{2}{|c|}{ Other $(\mathrm{N}=1487)$} & \multicolumn{2}{|c|}{ Total $(\mathrm{N}=9680)$} \\
\hline & $\mathrm{N}$ & $\%$ & $\mathrm{~N}$ & $\%$ & $\mathrm{~N}$ & $\%$ & $\mathrm{~N}$ & $\%$ \\
\hline \multicolumn{9}{|l|}{ SGA $<10$ th } \\
\hline No & 3274 & 83.3 & 3580 & 84 & 1274 & 85.7 & 8128 & 84.0 \\
\hline Yes & 655 & 16.7 & 684 & 16 & 213 & 14.3 & 1552 & 16.0 \\
\hline \multicolumn{9}{|l|}{ Preterm birth } \\
\hline No & 3702 & 94.2 & 4058 & 95.2 & 1399 & 94.1 & 9159 & 94.6 \\
\hline Yes & 227 & 5.8 & 206 & 4.8 & 88 & 5.9 & 521 & 5.4 \\
\hline \multicolumn{9}{|l|}{ Age } \\
\hline$<20$ & 465 & 11.8 & 109 & 2.6 & 73 & 4.9 & 647 & 6.7 \\
\hline $21-34$ & 2964 & 75.4 & 3629 & 85.1 & 1219 & 82 & 7812 & 80.7 \\
\hline $35+$ & 500 & 12.7 & 526 & 12.3 & 195 & 13.1 & 1221 & 12.6 \\
\hline \multicolumn{9}{|l|}{ Parity } \\
\hline Nulliparous & 1977 & 52.1 & 1450 & 35.6 & 729 & 51.1 & 4156 & 44.7 \\
\hline $1-3$ & 1719 & 45.3 & 2303 & 56.5 & 659 & 46.2 & 4681 & 50.3 \\
\hline$>3$ & 100 & 2.6 & 322 & 7.9 & 38 & 2.7 & 460 & 4.9 \\
\hline Missing & 133 & 3.4 & 189 & 4.4 & 61 & 4.1 & 383 & 4 \\
\hline \multicolumn{9}{|l|}{ BMI } \\
\hline Underweight & 93 & 2.5 & 233 & 5.7 & 73 & 5.1 & 399 & 4.3 \\
\hline Normal & 1658 & 44.3 & 1854 & 45.7 & 721 & 50.6 & 4233 & 45.9 \\
\hline Overweight & 1080 & 28.9 & 1207 & 29.7 & 375 & 26.3 & 2662 & 28.9 \\
\hline Obese & 911 & 24.3 & 766 & 18.9 & 255 & 17.9 & 1932 & 20.9 \\
\hline Missing & 187 & 4.8 & 204 & 4.8 & 63 & 4.2 & 454 & 4.7 \\
\hline \multicolumn{9}{|l|}{ Marital status } \\
\hline Married & 1235 & 31.5 & 4151 & 97.4 & 1112 & 74.8 & 6498 & 67.2 \\
\hline Not married & 2691 & 68.5 & 112 & 2.6 & 375 & 25.2 & 3178 & 32.8 \\
\hline Missing & 3 & 0.1 & 1 & 0 & 0 & 0 & 4 & 0 \\
\hline \multicolumn{9}{|c|}{ Index of Multiple Deprivation } \\
\hline Quintiles 2-5 & 1929 & 49.1 & 869 & 20.4 & 484 & 32.5 & 3282 & 33.9 \\
\hline Quintile 1 & 1998 & 50.9 & 3394 & 79.6 & 1003 & 67.5 & 6395 & 66.1 \\
\hline Missing & 2 & 0.1 & 1 & 0 & 0 & 0 & 3 & 0 \\
\hline \multicolumn{9}{|l|}{ Education } \\
\hline Higher education & 2764 & 70.4 & 2967 & 69.8 & 1111 & 75.1 & 6842 & 70.8 \\
\hline Less education & 1162 & 29.6 & 1285 & 30.2 & 369 & 24.9 & 2816 & 29.2 \\
\hline Missing & 3 & 0.1 & 12 & 0.3 & 7 & 0.5 & 22 & 0.2 \\
\hline \multicolumn{9}{|l|}{ Migration history } \\
\hline Born in UK & 3808 & 98.4 & 1808 & 43.1 & 510 & 35.2 & 6126 & 64.4 \\
\hline Migrated before age 16 & 46 & 1.2 & 475 & 11.3 & 151 & 10.4 & 672 & 7.1 \\
\hline Migrated $\geq$ age 16 & 15 & 0.4 & 1911 & 45.6 & 788 & 54.4 & 2714 & 28.5 \\
\hline Missing & 60 & 1.5 & 70 & 1.6 & 38 & 2.6 & 168 & 1.7 \\
\hline \multicolumn{9}{|l|}{ Smoking in pregnancy } \\
\hline No & 2310 & 64.4 & 4048 & 96.7 & 1295 & 90.2 & 7653 & 83.1 \\
\hline Yes & 1279 & 35.6 & 137 & 3.3 & 140 & 9.8 & 1556 & 16.9 \\
\hline Missing & 340 & 8.7 & 79 & 1.9 & 52 & 3.5 & 471 & 4.9 \\
\hline \multicolumn{9}{|l|}{ Alcohol in pregnancy } \\
\hline No & 1239 & 31.6 & 4240 & 99.7 & 1112 & 75 & 6591 & 68.3 \\
\hline Yes & 2683 & 68.4 & 13 & 0.3 & 370 & 25 & 3066 & 31.7 \\
\hline Missing & 7 & 0.2 & 11 & 0.3 & 5 & 0.3 & 23 & 0.2 \\
\hline
\end{tabular}


Table 1 continued

\begin{tabular}{|c|c|c|c|c|c|c|c|c|}
\hline & \multicolumn{2}{|c|}{ White British $(\mathrm{N}=3929)$} & \multicolumn{2}{|c|}{ Pakistani $(\mathrm{N}=4264)$} & \multicolumn{2}{|c|}{ Other $(\mathrm{N}=1487)$} & \multicolumn{2}{|c|}{ Total $(\mathrm{N}=9680)$} \\
\hline & $\mathrm{N}$ & $\%$ & $\mathrm{~N}$ & $\%$ & $\mathrm{~N}$ & $\%$ & $\mathrm{~N}$ & $\%$ \\
\hline \multicolumn{9}{|c|}{ Managing financially } \\
\hline Yes & 3645 & 93.2 & 3915 & 92.4 & 1329 & 90.4 & 8889 & 92.4 \\
\hline No & 268 & 6.8 & 324 & 7.6 & 141 & 9.6 & 733 & 7.6 \\
\hline Missing & 16 & 0.4 & 25 & 0.6 & 17 & 1.1 & 58 & 0.6 \\
\hline \multicolumn{9}{|c|}{ Behind with bills } \\
\hline No & 3371 & 87.8 & 3724 & 91.2 & 1283 & 87.9 & 8378 & 89.3 \\
\hline Yes & 467 & 12.2 & 360 & 8.8 & 176 & 12.1 & 1003 & 10.7 \\
\hline Missing & 91 & 2.3 & 180 & 4.2 & 28 & 1.9 & 299 & 3.1 \\
\hline \multicolumn{9}{|c|}{ Risk of distress } \\
\hline No & 2781 & 83.0 & 2889 & 84.0 & 1046 & 84.7 & 6716 & 83.7 \\
\hline Yes & 569 & 17.0 & 551 & 16.0 & 189 & 15.3 & 1309 & 16.3 \\
\hline Missing & 579 & 14.7 & 824 & 19.3 & 252 & 16.9 & 1655 & 17.1 \\
\hline \multicolumn{9}{|c|}{ Risk of hopelessness } \\
\hline No & 3095 & 92.4 & 3002 & 87.3 & 1083 & 87.7 & 7180 & 89.5 \\
\hline Yes & 255 & 7.6 & 438 & 12.7 & 152 & 12.3 & 845 & 10.5 \\
\hline Missing & 579 & 14.7 & 824 & 19.3 & 252 & 16.9 & 1655 & 17.1 \\
\hline \multicolumn{9}{|l|}{ Diabetes } \\
\hline No & 3719 & 94.8 & 3784 & 88.9 & 1349 & 91.0 & 8852 & 91.6 \\
\hline Yes & 203 & 5.2 & 474 & 11.1 & 133 & 9.0 & 810 & 8.4 \\
\hline Missing & 7 & 0.2 & 6 & 0.1 & 5 & 0.3 & 18 & 0.2 \\
\hline \multicolumn{9}{|c|}{ Hypertension } \\
\hline No & 3483 & 92.3 & 3845 & 94.1 & 1335 & 93.7 & 8663 & 93.3 \\
\hline Yes & 289 & 7.7 & 241 & 5.9 & 90 & 6.3 & 620 & 6.7 \\
\hline Missing & 157 & 4 & 178 & 4.2 & 62 & 4.2 & 397 & 4.1 \\
\hline
\end{tabular}

\section{Results}

\section{Participant Demographics}

The demographic characteristics of the cohort are shown in Table 1 with $40.6 \%$ reporting to be White British, $44 \%$ Pakistani and $15.4 \%$ 'Other ethnicity'. The overall rate of PTB was $5.4 \%$. A lower proportion of Pakistani women experienced PTB (4.8\%) compared to either White British or Other ethnic groups (5.8 and 5.9\% respectively). The rate of SGA at $16 \%$ was higher than the $10 \%$ baseline and was similarly raised within each ethnic group.

More than $20 \%$ of the cohort was classified as obese with the highest rate being amongst White British women $(24.3 \%)$. A disproportionate number of women lived in the most deprived quintile as defined by the IMD (66.1\%), including $79.6 \%$ of Pakistani women and $50.9 \%$ of White British women. Almost $17 \%$ of women smoked at some time in the pregnancy, again with a considerable difference seen between White British (35.6\%) and Pakistani women
(3.3\%). Diabetes was more prevalent amongst Pakistani compared to White British women, whereas hypertension was slightly less prevalent.

Fewer White British women were at risk of hopelessness compared to either Pakistani or women of other ethnicities. More than $10 \%$ of all participants felt that they were behind with their bills and $7.6 \%$ reported that they were not managing financially.

\section{Small for Gestational Age}

Univariate and multivariate analyses for the whole cohort are presented in Table 2. The evidence found that a number of psychosocial factors were associated with increased risk of SGA on univariate analysis. These associations, however, were not sustained after full adjustment for other variables. In multivariate analysis, hypertension and smoking in pregnancy were both associated with a more than twofold increased risk of SGA and Pakistani ethnicity was found to be associated with a $50 \%$ increased risk of 
Table 2 Logistic regression models for SGA and PTB, whole cohort

\begin{tabular}{|c|c|c|c|c|c|c|c|c|}
\hline & \multicolumn{4}{|l|}{ SGA } & \multicolumn{4}{|l|}{ РTB } \\
\hline & \multicolumn{2}{|c|}{ Unadjusted } & \multicolumn{2}{|c|}{ Fully adjusted } & \multicolumn{2}{|c|}{ Unadjusted } & \multicolumn{2}{|c|}{ Fully adjusted } \\
\hline & OR & $95 \% \mathrm{CI}$ & OR & $95 \% \mathrm{CI}$ & OR & $95 \% \mathrm{CI}$ & OR & $95 \% \mathrm{CI}$ \\
\hline \multicolumn{9}{|l|}{ Age } \\
\hline $21-34$ & 0.92 & {$[0.74,1.14]$} & 1.21 & {$[0.95,1.53]$} & 0.81 & {$[0.58,1.12]$} & 1.19 & {$[0.83,1.71]$} \\
\hline $35+$ & 0.90 & {$[0.69,1.16]$} & 1.27 & {$[0.94,1.70]$} & 0.80 & {$[0.53,1.19]$} & 1.22 & {$[0.77,1.94]$} \\
\hline \multicolumn{9}{|l|}{ Parity } \\
\hline $1-3$ & 1.03 & {$[0.92,1.15]$} & 1.04 & {$[0.91,1.18]$} & 0.78 & {$[0.65,0.94]$} & 0.85 & {$[0.69,1.04]$} \\
\hline$>3$ & 0.94 & {$[0.72,1.24]$} & 0.87 & {$[0.64,1.18]$} & 0.50 & {$[0.29,0.84]$} & 0.48 & {$[0.27,0.84]$} \\
\hline \multicolumn{9}{|l|}{ BMI } \\
\hline Underweight & 0.90 & {$[0.67,1.21]$} & 0.88 & {$[0.66,1.19]$} & 1.63 & {$[1.12,2.39]$} & 1.68 & {$[1.14,2.47]$} \\
\hline Overweight & 1.10 & {$[0.96,1.26]$} & 1.09 & {$[0.95,1.26]$} & 0.92 & {$[0.73,1.14]$} & 0.87 & {$[0.69,1.09]$} \\
\hline Obese & 1.25 & {$[1.08,1.44]$} & 1.15 & {$[0.99,1.35]$} & 1.14 & {$[0.90,1.45]$} & 0.89 & {$[0.69,1.15]$} \\
\hline \multicolumn{9}{|l|}{ Ethnicity } \\
\hline Pakistani & 0.96 & {$[0.85,1.07]$} & 1.51 & {$[1.23,1.86]$} & 0.83 & {$[0.68,1.00]$} & 0.98 & {$[0.71,1.36]$} \\
\hline Other & 0.84 & {$[0.71,0.99]$} & 1.21 & {$[0.97,1.50]$} & 1.03 & {$[0.80,1.32]$} & 1.20 & {$[0.86,1.66]$} \\
\hline \multicolumn{9}{|l|}{ Migration history } \\
\hline Migrated before age 16 & 0.99 & {$[0.80,1.23]$} & 1.02 & {$[0.81,1.29]$} & 0.94 & {$[0.66,1.33]$} & 0.95 & {$[0.65,1.38]$} \\
\hline Migrated $\geq$ age 16 & 0.80 & {$[0.71,0.91]$} & 0.85 & {$[0.73,1.00]$} & 0.82 & {$[0.67,1.01]$} & 0.79 & {$[0.61,1.03]$} \\
\hline \multicolumn{9}{|l|}{ Health behaviours } \\
\hline Smoking in pregnancy & 2.14 & {$[1.88,2.44]$} & 2.40 & {$[2.04,2.82]$} & 1.54 & {$[1.25,1.91]$} & 1.48 & {$[1.14,1.92]$} \\
\hline Alcohol in pregnancy & 1.06 & {$[0.94,1.19]$} & 0.98 & {$[0.83,1.15]$} & 1.08 & {$[0.90,1.31]$} & 0.94 & {$[0.73,1.21]$} \\
\hline \multicolumn{9}{|l|}{ Psycho-social } \\
\hline Not married & 1.29 & {$[1.15,1.44]$} & 1.14 & {$[0.96,1.35]$} & 1.28 & {$[1.07,1.54]$} & 1.06 & {$[0.81,1.38]$} \\
\hline More deprived IMD & 1.23 & {$[1.10,1.39]$} & 1.13 & {$[0.99,1.28]$} & 1.27 & {$[1.04,1.54]$} & 1.29 & {$[1.05,1.59]$} \\
\hline Less education & 1.17 & {$[1.04,1.32]$} & 1.06 & {$[0.94,1.20]$} & 1.23 & {$[1.02,1.49]$} & 1.22 & {$[1.00,1.48]$} \\
\hline At risk for distress & 0.92 & {$[0.78,1.08]$} & 0.80 & {$[0.67,0.96]$} & 1.16 & {$[0.90,1.49]$} & 1.08 & {$[0.82,1.42]$} \\
\hline At risk of hopelessness & 1.21 & {$[1.02,1.45]$} & 1.21 & {$[0.99,1.49]$} & 1.09 & {$[0.80,1.47]$} & 0.99 & {$[0.72,1.38]$} \\
\hline Not managing financially & 1.25 & {$[1.03,1.51]$} & 1.12 & {$[0.91,1.38]$} & 1.51 & {$[1.13,2.01]$} & 1.45 & {$[1.06,1.98]$} \\
\hline Behind with bills & 1.31 & {$[1.10,1.55]$} & 1.07 & {$[0.89,1.29]$} & 1.16 & {$[0.87,1.53]$} & 1.01 & {$[0.74,1.37]$} \\
\hline \multicolumn{9}{|l|}{ Medical conditions } \\
\hline Diabetes & 0.69 & {$[0.55,0.85]$} & 0.68 & {$[0.54,0.85]$} & 1.54 & {$[1.17,2.02]$} & 1.72 & {$[1.29,2.30]$} \\
\hline Hypertension & 2.17 & {$[1.80,2.60]$} & 2.33 & {$[1.92,2.83]$} & 3.48 & {$[2.72,4.46]$} & 3.67 & {$[2.83,4.78]$} \\
\hline
\end{tabular}

The bold represents significant results

SGA. Diabetes on the other hand was found to be protective of SGA. In addition, in multivariate analysis, women who were at risk of mental distress were found to have a $20 \%$ reduced risk of SGA.

\section{Preterm Birth}

There was evidence that diabetes and hypertension in pregnancy were associated with a significantly increased risk of PTB. Also, being underweight and smoking in pregnancy were found to be positively associated with risk of PTB. A number of socio-economic factors showed univariate association with increased risk of PTB. Living in the most deprived quintile and having less education remained significantly associated after adjustment for potential confounders. Furthermore, women who reported that they were not managing financially were found to have a $45 \%$ increased risk of PTB.

\section{Stratified Analysis}

\section{White British}

For White British women, risk of distress was not found to be positively associated with risk of SGA. However, for those who smoked there was an almost threefold increased risk (Table 3). Smoking was also shown to be associated 
Table 3 Risk factors for SGA and PTB, White British women

\begin{tabular}{|c|c|c|c|c|c|c|c|c|}
\hline & \multicolumn{4}{|l|}{ SGA } & \multicolumn{4}{|l|}{ РTB } \\
\hline & \multicolumn{2}{|c|}{ Unadjusted } & \multicolumn{2}{|c|}{ Fully adjusted } & \multicolumn{2}{|c|}{ Unadjusted } & \multicolumn{2}{|c|}{ Fully adjusted } \\
\hline & OR & $95 \% \mathrm{CI}$ & OR & $95 \%$ CI & OR & $95 \% \mathrm{CI}$ & OR & $95 \% \mathrm{CI}$ \\
\hline \multicolumn{9}{|l|}{ BMI } \\
\hline Underweight & 0.73 & {$[0.38,1.39]$} & 0.60 & {$[0.31,1.15]$} & 1.83 & {$[0.92,3.64]$} & 1.72 & {$[0.85,3.05]$} \\
\hline Overweight & 1.16 & {$[0.95,1.43]$} & 1.19 & {$[0.96,1.48]$} & 0.86 & {$[0.61,1.20]$} & 0.82 & {$[0.58,1.16]$} \\
\hline Obese & 1.14 & {$[0.92,1.41]$} & 1.11 & {$[0.88,1.39]$} & 0.84 & {$[0.59,1.21]$} & 0.67 & {$[0.45,0.98]$} \\
\hline \multicolumn{9}{|l|}{ Health behaviours } \\
\hline Smoking in pregnancy & 2.81 & {$[2.35,3.37]$} & 2.78 & {$[2.28,3.40]$} & 1.46 & {$[1.11,1.93]$} & 1.38 & {$[1.01,1.88]$} \\
\hline Alcohol in pregnancy & 1.06 & {$[0.88,1.27]$} & 1.03 & {$[0.85,1.25]$} & 0.91 & {$[0.69,1.21]$} & 0.94 & {$[0.70,1.26]$} \\
\hline \multicolumn{9}{|l|}{ Psycho-social } \\
\hline Not married & 1.60 & {$[1.32,1.95]$} & 1.20 & {$[0.97,1.50]$} & 1.24 & {$[0.92,1.67]$} & 1.04 & {$[0.74,1.46]$} \\
\hline More deprived IMD & 1.38 & {$[1.17,1.64]$} & 1.10 & {$[0.92,1.33]$} & 1.43 & {$[1.09,1.88]$} & 1.35 & {$[1.01,1.82]$} \\
\hline Less education & 1.25 & {$[1.05,1.50]$} & 0.99 & {$[0.81,1.20]$} & 1.26 & {$[0.95,1.68]$} & 1.16 & {$[0.86,1.56]$} \\
\hline At risk for distress & 1.11 & {$[0.88,1.40]$} & 0.94 & {$[0.71,1.23]$} & 1.18 & {$[0.83,1.69]$} & 1.07 & {$[0.71,1.63]$} \\
\hline At risk of hopelessness & 1.34 & {$[0.99,1.83]$} & 1.17 & {$[0.82,1.69]$} & 1.23 & {$[0.75,2.01]$} & 1.09 & {$[0.61,1.95]$} \\
\hline Not managing financially & 1.31 & {$[0.96,1.78]$} & 1.01 & {$[0.72,1.41]$} & 1.58 & {$[1.01,2.48]$} & 1.54 & {$[0.95,2.49]$} \\
\hline Behind with bills & 1.49 & {$[1.17,1.89]$} & 1.12 & {$[0.86,1.46]$} & 1.12 & {$[0.75,1.67]$} & 0.93 & {$[0.61,1.44]$} \\
\hline \multicolumn{9}{|l|}{ Medical conditions } \\
\hline Diabetes & 0.59 & {$[0.38,0.93]$} & 0.61 & {$[0.35,0.97]$} & 1.66 & {$[1.00,2.74]$} & 1.85 & {$[1.10,3.12]$} \\
\hline Hypertension & 1.54 & {$[1.16,2.05]$} & 1.77 & {$[1.31,2.39]$} & 2.41 & {$[1.63,3.58]$} & 2.90 & {$[1.91,4.40]$} \\
\hline
\end{tabular}

The bold represents significant results

with PTB, although the strength of association was not as strong. In multivariate analysis, obesity in White British women was found to be protective for PTB.

\section{Pakistani}

In Pakistani women, risk of distress was found to be protective of SGA. This association persisted after full adjustment (Table 4). There was little evidence of an association between other psychosocial factors and SGA. Smoking, diabetes and hypertension were all found to be positively associated with increased risk of preterm birth.

\section{Other Ethnic Groups}

For women of other ethnic origins, hypertension, smoking in pregnancy and living in the most deprived quintile were all associated with an increased risk of SGA (Table 5). Migrating to the United Kingdom after the age of 16 was found to be protective of SGA. Hypertension in pregnancy and being underweight were both strongly associated with increased risk of PTB for this group, with no other factors reaching statistical significance.

\section{Discussion}

This study provides an insight into different factors (medical, behavioral, and psychosocial) that impact on perinatal outcome in an ethnically diverse and economically deprived population. Overall there was a lower than expected rate of PTB in the cohort $(5.6 \%)$ compared to the national average (7.2\%) [24]. This may have been, in part, due to recruitment taking place at around 26-28 weeks' gestation, excluding women who went into extreme preterm labour and the exclusion of multiple pregnancies from the analysis.

Conversely, there were a greater proportion of SGA babies $(16 \%)$ than the national average for the UK population. The higher rate in this sample possibly reflects the high prevalence of risk factors associated with SGA within the pregnant population of Bradford as a whole. Bradford is a socially deprived city, with two-thirds of the population living in the most deprived quintile as defined by the nationally derived IMD.

This study is consistent with other that have described an association between hypertension in pregnancy and both SGA and PTB within all ethnic groups [2]. In line with other studies which have suggested that diabetes in pregnancy increases the risk of indicated preterm birth, we also found an association between diabetes and PTB [37]. 
Table 4 Risk factors for SGA and PTB, women of Pakistani origin

\begin{tabular}{|c|c|c|c|c|c|c|c|c|}
\hline & \multicolumn{4}{|l|}{ SGA } & \multicolumn{4}{|l|}{ PTB } \\
\hline & \multicolumn{2}{|c|}{ Unadjusted } & \multicolumn{2}{|c|}{ Fully adjusted } & \multicolumn{2}{|c|}{ Unadjusted } & \multicolumn{2}{|c|}{ Fully adjusted } \\
\hline & OR & $95 \%$ CI & OR & $95 \%$ CI & OR & $95 \% \mathrm{CI}$ & OR & $95 \% \mathrm{CI}$ \\
\hline \multicolumn{9}{|l|}{ BMI } \\
\hline Underweight & 1.06 & {$[0.73,1.53]$} & 1.07 & {$[0.74,1.56]$} & 1.35 & {$[0.75,2.42]$} & 1.34 & {$[0.73,2.45]$} \\
\hline Overweight & 1.08 & {$[0.89,1.32]$} & 1.06 & {$[0.86,1.30]$} & 0.95 & {$[0.67,1.35]$} & 0.92 & {$[0.64,1.32]$} \\
\hline Obese & 1.25 & {$[1.00,1.56]$} & 1.14 & {$[0.89,1.45]$} & 1.21 & {$[0.83,1.76]$} & 0.99 & {$[0.65,1.50]$} \\
\hline Smoking in pregnancy & 1.13 & {$[0.72,1.77]$} & 1.11 & {$[0.70,1.76]$} & 2.42 & {$[1.37,4.27]$} & 2.26 & {$[1.24,4.14]$} \\
\hline \multicolumn{9}{|l|}{ Migration history } \\
\hline Migrated before age 16 & 1.07 & {$[0.81,1.40]$} & 1.08 & {$[0.82,1.43]$} & 0.96 & {$[0.61,1.50]$} & 1.01 & {$[0.63,1.61]$} \\
\hline Migrated $\geq$ age 16 & 0.84 & {$[0.71,1.00]$} & 0.86 & {$[0.71,1.03]$} & 0.74 & {$[0.55,1.00]$} & 0.78 & {$[0.56,1.07]$} \\
\hline \multicolumn{9}{|l|}{ Psycho-social } \\
\hline Not married & 1.36 & {$[0.86,2.17]$} & 1.26 & {$[0.77,2.06]$} & 1.75 & {$[0.87,3.52]$} & 1.23 & {$[0.58,2.61]$} \\
\hline More deprived IMD & 1.05 & {$[0.85,1.29]$} & 1.02 & {$[0.83,1.26]$} & 1.22 & {$[0.84,1.76]$} & 1.19 & {$[0.82,1.74]$} \\
\hline Less education & 1.08 & {$[0.91,1.29]$} & 1.12 & {$[0.93,1.35]$} & 1.14 & {$[0.85,1.54]$} & 1.26 & {$[0.92,1.73]$} \\
\hline At risk for distress & 0.71 & {$[0.54,0.93]$} & 0.65 & {$[0.48,0.88]$} & 0.99 & {$[0.64,1.52]$} & 0.91 & {$[0.58,1.42]$} \\
\hline At risk of hopelessness & 1.10 & {$[0.84,1.45]$} & 1.22 & {$[0.90,1.65]$} & 1.27 & {$[0.79,2.06]$} & 1.16 & {$[0.67,2.01]$} \\
\hline Not managing financially & 1.16 & {$[0.86,1.56]$} & 1.23 & {$[0.90,1.69]$} & 1.31 & {$[0.82,2.12]$} & 1.24 & {$[0.74,2.08]$} \\
\hline Behind with bills & 0.95 & {$[0.71,1.29]$} & 0.94 & {$[0.68,1.29]$} & 1.20 & {$[0.75,1.91]$} & 1.22 & {$[0.74,2.00]$} \\
\hline \multicolumn{9}{|l|}{ Medical conditions } \\
\hline Diabetes & 0.74 & {$[0.56,0.98]$} & 0.71 & {$[0.53,0.95]$} & 1.48 & {$[1.00,2.19]$} & 1.59 & {$[1.04,2.40]$} \\
\hline Hypertension & 3.03 & {$[2.30,4.00]$} & 3.08 & {$[2.30,4.10]$} & 5.27 & {$[3.65,7.60]$} & 5.48 & {$[3.71,8.10]$} \\
\hline
\end{tabular}

The bold represents significant results

Our findings showed a significant association between financial strain ('not managing financially') and risk of PTB, with a similar degree of association to smoking. Financial concerns have been shown to be independently associated with an increased risk of psychological distress in pregnancy $[25,26]$. Although social deprivation has long been associated with poor perinatal outcome [7], no other studies have examined the subjective assessment of financial management and perinatal outcomes. The report by the Royal College of Paediatrics and Child Health highlights the role of poverty and in particular social inequality in increasing the risk of poor perinatal and infant outcomes [34].

The relationship between poor psychological health (depression and stress) and adverse perinatal outcomes, in particular PTB, is becoming an area of increasing interest [16]. Women who show signs of depression as assessed by the Edinburgh Postnatal Depression scale have been found to have an increased risk of PTB and SGA [19]. A recent international cohort study also noted an association between stress and anxiety in pregnancy and an increased risk of SGA [17].

The apparently protective effect of maternal distress on risk of SGA in the Pakistani cohort is surprising, particularly as it was not evident on univariate analysis. An explanation for this may be that the GHQ-28 does not identify maternal distress well at this stage in pregnancy, that there are different cultural norms in the way the distress is described, or that it is a chance finding. The other variable we derived from the GHQ-28 (risk of hopelessness) showed trends in the expected direction (distress $=$ adverse birth outcome), and, although we did not use a validated measure of hopelessness and there is likely to be variation in the relationship between hopelessness and mental disorder, there is alignment between the two [5, 36].

A protective association was found between obesity and PTB amongst White British women in this study, but not within the other ethnic groups. Previous studies have shown different findings with regard to the association between obesity and PTB, with some indicating an increased risk [37] and others, a lower risk [18]. It may be that the risks are population specific, relating to different pathophysiological pathways, with a reduced risk for spontaneous PTB and an increased risk for indicated PTB [23]. Therefore, when adjustments are made for related factors such as hypertension and diabetes, as in this study, the protective effect of being obese, but healthy, is more clearly visible than in other studies where reasons for indicated prematurity may not have been excluded from the adjusted analyses. 
Table 5 Risk factors for SGA and PTB, women of other ethnic origin

\begin{tabular}{|c|c|c|c|c|c|c|c|c|}
\hline & \multicolumn{4}{|l|}{ SGA } & \multicolumn{4}{|l|}{ РTB } \\
\hline & \multicolumn{2}{|c|}{ Unadjusted } & \multicolumn{2}{|c|}{ Fully adjusted } & \multicolumn{2}{|c|}{ Unadjusted } & \multicolumn{2}{|c|}{ Fully adjusted } \\
\hline & OR & $95 \% \mathrm{CI}$ & OR & $95 \% \mathrm{CI}$ & $\mathrm{OR}$ & $95 \% \mathrm{CI}$ & OR & $95 \% \mathrm{CI}$ \\
\hline \multicolumn{9}{|l|}{ BMI } \\
\hline Underweight & 0.67 & {$[0.30,1.51]$} & 0.67 & {$[0.29,1.53]$} & 3.33 & {$[1.55,7.12]$} & 3.58 & {$[1.63,7.87]$} \\
\hline Overweight & 0.92 & {$[0.63,1.33]$} & 0.90 & {$[0.62,1.33]$} & 1.01 & {$[0.55,1.86]$} & 0.93 & {$[0.50,1.75]$} \\
\hline Obese & 1.62 & {$[1.13,2.34]$} & 1.45 & {$[0.97,2.15]$} & 2.33 & {$[1.33,4.09]$} & 1.63 & $(0.87,3.05]$ \\
\hline \multicolumn{9}{|l|}{ Migration history } \\
\hline Migrated before age 16 & 0.88 & $(0.53,1.46]$ & 0.92 & $(0.54,1.56]$ & 0.52 & $(0.20,1.35]$ & 0.44 & $(0.16,1.21]$ \\
\hline Migrated $\geq$ age 16 & 0.68 & $(0.50,0.94]$ & 0.70 & $(0.50,0.98]$ & 0.99 & $(0.62,1.56]$ & 0.94 & $(0.57,1.54]$ \\
\hline \multicolumn{9}{|l|}{ Health behaviours } \\
\hline Smoking in pregnancy & 2.57 & $(1.73,3.82]$ & 2.62 & $(1.62,4.24]$ & 0.96 & $(0.45,2.04]$ & 0.88 & $(0.37,2.10]$ \\
\hline Alcohol in pregnancy & 0.95 & $(0.68,1.33]$ & 0.79 & $(0.53,1.18]$ & 1.00 & $(0.61,1.65]$ & 1.06 & $(0.59,1.90]$ \\
\hline \multicolumn{9}{|l|}{ Psycho-social } \\
\hline Not married & 1.23 & $(0.89,1.70]$ & 0.85 & $(0.56,1.28]$ & 1.19 & $(0.74,1.92]$ & 1.13 & $(0.62,2.04]$ \\
\hline More deprived IMD & 1.50 & $(1.08,2.09]$ & 1.45 & $(1.02,2.05]$ & 1.39 & $(0.85,2.26]$ & 1.36 & $(0.81,2.28]$ \\
\hline Less education & 1.22 & {$[0.88,1.68]$} & 1.10 & {$[0.78,1.56]$} & 1.44 & {$[0.90,2.29]$} & 1.47 & {$[0.89,2.43]$} \\
\hline At risk for distress & 1.17 & {$[0.78,1.77]$} & 0.96 & {$[0.60,1.55]$} & 1.64 & {$[0.96,2.81]$} & 1.71 & {$[0.92,3.17]$} \\
\hline At risk of hopelessness & 1.54 & {$[0.99,2.38]$} & 1.39 & {$[0.86,2.27]$} & 1.03 & {$[0.51,2.11]$} & 0.74 & {$[0.33,1.66]$} \\
\hline Not managing financially & 1.43 & {$[0.91,2.25]$} & 1.13 & {$[0.68,1.89]$} & 1.72 & {$[0.93,3.20]$} & 1.54 & {$[0.76,3.13]$} \\
\hline Behind with bills & 1.59 & {$[1.07,2.38]$} & 1.19 & {$[0.76,1.87]$} & 1.18 & {$[0.63,2.22]$} & 0.92 & {$[0.46,1.85]$} \\
\hline \multicolumn{9}{|l|}{ Medical conditions } \\
\hline Diabetes & 0.68 & {$[0.38,1.21]$} & 0.64 & {$[0.35,1.17]$} & 1.85 & {$[1.00,3.43]$} & 1.60 & {$[0.81,3.17]$} \\
\hline Hypertension & 2.43 & {$[1.49,3.96]$} & 2.32 & {$[1.38,3.90]$} & 3.56 & {$[1.90,6.66]$} & 3.35 & {$[1.65,6.80]$} \\
\hline
\end{tabular}

The bold represents significant results

Smoking is a well-established known risk factor for increased risk of SGA [15]. A high proportion of White British women smoked at some stage in their pregnancy (35\%), and this was found to be the most significant risk factor for SGA amongst this population RR 2.78 (CI 2.28-3.40). However in the Pakistani population (where only $3.3 \%$ of women smoked), no association was found RR $1.11(0.70-1.76)$.

Migration after the age of 16 was also found to be protective of SGA for non-Pakistani ethnic groups. A 'healthy migrant effect', which suggests that babies born to foreign-born women may have better outcomes than those born to 'native-born' women, has been previously described and debated $[3,33]$ and may relate to differences in health behaviour amongst newer migrants [14]. The findings from this study reinforce the need for careful analysis of the ethnic, geographic and socio-economic context of the populations observed.

\section{Strengths and Limitations}

This was a large multi-ethnic cohort study which was shown to be representative of the population of Bradford as a whole. Data were collected prospectively and linked datasets allowed for the collection of relevant perinatal outcomes. This allowed us to control for a wide range of covariates. Although a number of perinatal outcomes were captured, it was not possible to distinguish between spontaneous and medically indicated preterm birth which limited detailed analysis of specific risk factors. In addition, there were a number of missing data, particularly relating to the GHQ-28, and the process of imputation may have impacted on the findings; although when we ran models using only those with the complete dataset, the findings were not significantly altered. A further limitation to this study is that responses to the GHQ-28 in multi-ethnic populations may vary between different ethnic groups and language of administration, independent of the level of actual distress [25, 26]. Other research has reported variation in the expected psychometric properties of the GHQ-28 in pregnant Nigerian women [1] and reduced reliability of the questionnaire when applied late in pregnancy [20]. We potentially mitigated language and interpretation effects by deriving centiles from scores computed within ethno-language groups to categorise risk of distress, and limited the risk of hopelessness variable to questions that had been shown to relate to similar concepts across ethno-language groups [25, 26]. We cannot, however, 
rule out the possibility that increased measurement error due to pregnancy, or our multi-ethnic sample, or both factors, affected our results.

\section{Conclusion}

This study confirms certain known risk factors for adverse pregnancy outcome. However, it also identifies some previously undocumented and unexpected findings. This includes an association between maternal financial strain and risk of PTB that is as high as that for smoking, which, if generalisable, has important social implications. It also discerns additional relationships in specific subgroups: an unexpectedly lower rate of SGA in the offspring of women of Pakistani origin who reported distress and a reduced rate of PTB amongst White British women who were obese. There is a need for further ethnic-specific studies to understand the mechanistic pathways for psychosocial stress and poor pregnancy outcome in order to better inform public health policy.

Acknowledgments Born in Bradford is only possible because of the enthusiasm and commitment of the Children and Parents in BiB. We are grateful to all the participants, health professionals and researchers who have made Born in Bradford happen.

Funding This work was supported by a National Institute of Health Research (NIHR) Collaboration for Leadership in Applied Health Research and Care (CLAHRC) implementation grant [KRD/012/001/ 006], an NIHR applied programme grant [RP-PG-0407-10044] and an Economic and Social Research Council (ESRC) research grant [RES177-25-0016]. The views expressed are those of the authors and not necessarily those of the NHS, the NIHR or the Department of Health. The funders had no role in study design, data collection and analysis.

\section{Compliance with Ethical Standards}

Conflict of interest The authors have no conflicts of interests or corporate sponsors to disclose.

Ethical Approval Ethical approval was granted by the Bradford Research Ethics Committee (Ref 07/H1302/112).

Open Access This article is distributed under the terms of the Creative Commons Attribution 4.0 International License (http://crea tivecommons.org/licenses/by/4.0/), which permits unrestricted use, distribution, and reproduction in any medium, provided you give appropriate credit to the original author(s) and the source, provide a link to the Creative Commons license, and indicate if changes were made.

\section{References}

1. Aderibigbe, Y. A., Riley, W., Lewin, T., \& Gureje, O. (1996). Factor structure of the 28-item general health questionnaire in a sample of antenatal women. International Journal of Psychiatry in Medicine, 26(3), 263-269.
2. Allen, V., Joseph, K., Murphy, K., Magee, L., \& Ohlsson, A. (2004). The effect of hypertensive disorders in pregnancy on small for gestational age and stillbirth: A population based study. BMC Pregnancy and Childbirth, 4(1), 17.

3. Auger, N., Luo, Z. C., Platt, R. W., \& Daniel, M. (2008). Do mother's education and foreign born status interact to influence birth outcomes? Clarifying the epidemiological paradox and the healthy migrant effect. Journal of Epidemiology and Community Health, 62(5), 402-409.

4. Barker, D. J. (2006). Adult Consequences of Fetal Growth Restriction. Clinical Obstetrics and Gynecology, 49(2), 270-283.

5. Beck, A. L., Steer, R. A., Beck, J. S., \& Newman, C. (1993). Hopelessness, depression, suicidal ideation, and clinical diagnosis of depression. Suicide and Life-Threatening Behavior, 23(2), 139-145.

6. Bryant, M., Santorelli, G., Lawlor, D. A., Farrar, D., Tuffnell, D., Bhopal, R., \& Wright, J. (2014). A comparison of South Asian specific and established BMI thresholds for determining obesity prevalence in pregnancy and predicting pregnancy complications: Findings from the Born in Bradford cohort. International Journal of Obesity, 38(3), 444-450.

7. Farley, T. A., Mason, K., Rice, J., Habel, J. D., Scribner, R., \& Cohen, D. A. (2006). The relationship between the neighbourhood environment and adverse birth outcomes. Paediatric and Perinatal Epidemiology, 20(3), 188-200.

8. Gardosi, J., Chang, A., Kalyan, B., Sahota, D., \& Symonds, E. M. (1992). Customised antenatal growth charts. Lancet, 339(8788), 283-287.

9. Gardosi, J., Madurasinghe, V., Williams, M., Malik, A., \& Francis, A. (2013). Maternal and fetal risk factors for stillbirth: population based study. BMJ, 346, f108.

10. GL Assessment. Frequently asked questions about the general health questionnaire: GL Assessment. From http://www.glassessment.co.uk/products/general-health-questionnaire/faqs? css $=1$.

12. Goldberg, D. P., \& Hillier, V. F. (1979). A scaled version of the General Health Questionnaire. Psychological Medicine, 9(1), 139-145.

13. Goldenberg, R. L., Culhane, J. F., Iams, J. D., \& Romero, R. (2008). Epidemiology and causes of preterm birth. Lancet, 371, $75-84$.

14. Hawkins, S. S., Lamb, K., Cole, T. J., \& Law, C. (2008). Influence of moving to the UK on maternal health behaviours: prospective cohort study. BMJ, 336(7652), 1052-1055.

15. Heaman, M., Kingston, D., Chalmers, B., Sauve, R., Lee, L., \& Young, D. (2013). Risk factors for preterm birth and small-forgestational-age births among Canadian women. Paediatric and Perinatal Epidemiology, 27(1), 54-61.

16. Hobel, C. J., Goldstein, A., \& Barrett, E. S. (2008). Psychosocial stress and pregnancy outcome. Clinical Obstetrics and Gynecology, 51(2), 333-348.

17. Khashan, A. S., Everard, C., McCowan, L. M. E., Dekker, G., Moss-Morris, R., Baker, P. N., et al. (2014). Second-trimester maternal distress increases the risk of small for gestational age. Psychological Medicine, 44(13), 2799-2810.

18. Khashan, A. S., \& Kenny, L. C. (2009). The effects of maternal body mass index on pregnancy outcome. European Journal of Epidemiology, 24, 697-705.

19. Kim, D. R., Sockol, L. E., Sammel, M. D., Kelly, C., Moseley, M., \& Epperson, C. N. (2013). Elevated risk of adverse obstetric outcomes in pregnant women with depression. Archives of Women's Mental Health, 16(6), 475-482.

20. Kitamura, T., Shima, S., Sugawara, M., \& Toda, M. A. (1994). Temporal variation of validity of self-rating questionnaires: repeated use of the General Health Questionnaire and Zung's Self-rating Depression Scale among women during antenatal and 
postnatal periods. Acta Psychiatrica Scandinavica, 90(6), 446-450.

21. Moser, K., Stanfield, K. M., \& Leon, D. A. (2008). Birthweight and gestational age by ethnic group, England and Wales 2005: introducing new data on births. Health Statistics Quarterly, 39, 23-31. Office for National Statistics.

22. Mulder, E. J. H., Robles de Medina, P. G., Huizink, A. C., Van den Bergh, B. R. H., Buitelaar, J. K., \& Visser, G. H. A. (2002). Prenatal maternal stress: effects on pregnancy and the (unborn) child. Early Human Development, 70(1-2), 3-14.

23. Nohr, E. A., Bech, B. H., Vaeth, M., Rasmussen, K. M., Henriksen, T. B., \& Olsen, J. (2007). Obesity, gestational weight gain and preterm birth: a study within the Danish National Birth Cohort. Paediatric and Perinatal Epidemiology, 21(1), 5-14.

24. Office for National Statistics (ONS) (2013). Gestation-Specific Infant Mortality in England and Wales 2011. From http://www. ons.gov.uk/ons/publications/re-reference-tables.html?edition=tcm $\%$ 3A77-320891.

25. Prady, S. L., Miles, J. N., Pickett, K. E., Fairley, L., Bloor, K., Gilbody, S., et al. (2013). The psychometric properties of the subscales of the GHQ-28 in a multi-ethnic maternal sample: results from the Born in Bradford cohort. BMC Psychiatry, 13, 55.

26. Prady, S. L., Pickett, K. E., Croudace, T., Fairley, L., Bloor, K., Gilbody, S., et al. (2013). Psychological distress during pregnancy in a multi-ethnic community: findings from the born in Bradford cohort study. PLoS One, 8(4), e60693-e60693.

27. RCOG (2013) The Investigation and Management of the Smallfor-Gestational-Age Fetus. Green-top Guideline No 31.

28. Shah, P. S., Zao, J., \& Ali, S. (2011). Maternal marital status and birth outcomes: a systematic review and meta-analyses. Maternal and Child Health Journal, 15(7), 1097-1109.
29. Steer, P. (2005). The epidemiology of preterm labour. BJOG: An International Journal of Obstetrics and Gynaecology, 112, 1-3.

30. Weightman, A. L., Morgan, H. E., Shepherd, M. A., Kitcher, H., Roberts, C., \& Dunstan, F. D. (2012). Social inequality and infant health in the UK: Systematic review and meta-analyses. BMJ Open, 2(3), e00064.

31. WHO. (2000). Obesity: preventing and managing the global epidemic. report of a WHO Consultation. Geneva: World Health Organisation.

32. WHO Expert Consultation. (2004). Appropriate body-mass index for Asian populations and its implications for policy and intervention strategies. Lancet, 363(9403), 157-163.

33. Wingate, M. S., \& Alexander, G. R. (2006). The healthy migrant theory: Variations in pregnancy outcomes among US-born migrants. Social Science and Medicine, 62(2), 491-498.

34. Wolfe, I., MacFarlane, A., Donkin, A., Marmot, M. \& Viner, R. (2014). Why children die: deaths in infants, children and young people in the Uk Part A: Royal College of Paediatrics and Child Health and National Children's Bureau.

35. Wright, J., Small, N., Raynor, P., Tuffnell, D., Bhopal, R., Cameron, N., et al. (2012). Cohort profile: The Born in Bradford multi-ethnic family cohort study. International Journal of Epidemiology, 42, 978-991.

36. Zahn R, Lythe KE, Gethin JA, Green S, Deakin JF, Young AH, Moll J (2015) The role of self-blame and worthlessness in the psychopathology of major depressive disorder. J Affect Disord. 186:337-341. doi: 10.1016/j.jad.2015.08.001.

37. Zhang, Y. P., Liu, X. H., Gao, S. H., Wang, J. M., Gu, Y. S., Zhang, J. Y., et al. (2012). Risk factors for preterm birth in five Maternal and Child Health hospitals in Beijing. PLoS ONE, $7(12)$, e52780. 